\title{
Research on Evolution Characteristics of Unloading Energy in Excavation Face of High-Stress Pillar
}

\author{
Chenyang Liu, ${ }^{1,2}$ Guanghua Sun $\mathbb{D}^{1,2}$ Peng Liang, ${ }^{1,2}$ Yufan Feng $\mathbb{D}^{1,2}$ Yue Wang $\mathbb{D}^{1,2}$ \\ and Jinxia Zhang ${ }^{1,2}$ \\ ${ }^{1}$ School of Mining Engineering, North China University of Technology, Beijing, China \\ ${ }^{2}$ Key Laboratory of Mining Development and Safety Technology of Hebei Province, Tangshan, China \\ Correspondence should be addressed to Guanghua Sun; czsgh110@163.com
}

Received 10 November 2021; Accepted 4 January 2022; Published 21 January 2022

Academic Editor: Pengfei Wang

Copyright ( 92022 Chenyang Liu et al. This is an open access article distributed under the Creative Commons Attribution License, which permits unrestricted use, distribution, and reproduction in any medium, provided the original work is properly cited.

\begin{abstract}
In the mining process of the stage empty field subsequent filling mining method, aiming at the problem of unloading failure and instability of the excavation face of the high-stress ore pillar, the theory of unloading stress component is introduced and combined with the energy release theory to explore the unloading failure mechanism of the excavation face of the ore pillar. The results show the following. (1) The degree of accumulation of strain energy in the pillar is related to the tangential stress. After the peak of the tangential stress, the energy changes from accumulation to release, indicating that energy release is the main cause of pillar damage. (2) In pillar unloading, there are 4 typical characteristic areas of stress during the loading process: crushing area, shaping area, elastic area, and original rock stress area. The energy accumulation area and the stress component area show good correspondence, and they all appear from the top to the bottom of the pillar. At 1/4, the starting point of unloading failure can be determined. (3) The mutation mechanism in the process of energy release is related to the time effect of tangential stress. On the contrary, the greater the tangential stress is, the longer the elastic zone lasts, and the more significant the energy accumulation is. Also, the increase in tangential stress will lead the energy release time becomes shorter, and a large amount of accumulated energy is released in a short time, causing local instability and destruction of the pillar, and eventually spreads to the whole.
\end{abstract}

\section{Introduction}

The staged empty field subsequent filling method integrates many advantages of the empty field method and the filling method. It has the advantages of large stage height, large number of ore collapse at one time, and high mining efficiency. It has become one of the main development trends of large underground mines, especially metallurgical mines. When returning to the ore body using the staged empty field subsequent filling method, the ore blocks are divided into ore houses and ore pillars. Go back to the mining room in one step, and go back to the mining pillar in the second step to form an underground space structure system of backfillpillar-backfill. During the coordinated bearing process of the backfill and the pillar, a large amount of elastic strain energy accumulates in the pillar. As the pillars are mined one by one in order and then filled, the stress on the unmined pillars continues to concentrate, and the internal elastic strain energy continues to build up. In this high-stress state, once the excavation surface (cutting groove) of the pillar is formed, the transient release of strain energy causes the pillar to be damaged and unstable [1], which directly threatens the safety of construction personnel and equipment. Therefore, in-depth analysis of the transient unloading failure mechanism of the mining pillar excavation face has important theoretical and practical significance for preventing underground accidents.

From the energy point of view, the destruction of rock mass is accompanied by the transfer of energy. By monitoring the energy change during the excavation and unloading of the pillar, studying the law of energy evolution is an effective way to solve practical problems [2-4]. Scholars at home and abroad have done a lot of research on the energy release of rock mass unloading. Cook et al. [5-7] in 1966 
explored and established a method for calculating the internal energy release rate of a rock mass during excavation and unloading. Based on this, Klishin et al. [8-11] analyzed the energy flow law of surrounding rock during the unloading process of rock mass under different boundary constraints, aiming at the energy behavior of surrounding rock. An-Zeng Hua et al. [12-15] , based on the determination of the energy storage limit of surrounding rock, analyzed the internal relationship between surrounding rock failure and energy release and explored the impact of unloading on surrounding rock at different confining pressures and at different distances from the excavation surface. Based on the stress unloading mechanism of deep mining, Fu et al. [16] established a deep mined-out area instability analysis model, used the local energy release theory and cusp catastrophe to analyze the energy evolution law during the unloading process of the mined-out area, and obtained the surrounding rock. The theory is based on energy release in the horizontal direction and energy concentration in the vertical direction.

The above research shows that unloading of rock mass will cause the release of accumulated energy, and the degree of release determines the degree of rock mass destruction. For unloading problems encountered in engineering, the energy migration and accumulation are often difficult to predict. Existing experimental studies have shown that the law of energy accumulation and release is directly related to the changes in the mechanical environment of rock masses. According to the different stress conditions of the rock mass, it can be divided into broken zone, plastic zone, elastic zone, and original rock stress zone, with different forces. This can lead to different patterns of energy accumulation and release [17]. Therefore, for energy changes during unloading, we should focus on studying the characteristics of energy accumulation and release inside the rock mass when the stress environment changes, which is of great significance for revealing the transient unloading failure mechanism of pillar excavation.

Use the theory of unloading stress components to carry out the transient unloading numerical simulation test of the pillar excavation under different stress components, establish the pillar mining model under the subsequent filling environment according to engineering examples, and analyze the energy evolution law and its time effect at different stages of mining. The point catastrophe model is used to obtain the basis for determining the instability of the pillar energy mutation and focusing on the influence of the tangential stress component on the energy mutation process of the pillar and further deepen the research on the transient unloading instability failure mechanism of the pillar excavation.

\section{Cusp Catastrophe Theory Based on Local Energy Release}

2.1. Unloading Local Energy Release Theory. In order to ensure the ore pillars' caving laterally, a cutting groove is arranged in the first mining section of the pillar, and the excavation of the cutting groove re-adjusts the internal stress and deformation of the pillar until a new equilibrium state is reached. The two stable states before and after excavation are defined as state I and state II.

First, the variational $\delta$ is used to express the stress, displacement, and surface force vector caused by excavation [18], and the relationship between it and the unit displacement, stress, and surface force vector before and after the excavation is expressed as

$$
u_{i}^{1}=u_{i}^{p}+\delta u_{i} \tau_{i j}^{1}=\tau_{i j}^{p}+\delta \tau_{i j} R_{i}^{1}=R_{i}^{p}+\delta R_{i} T_{i}^{1}=T_{i}^{p}+\delta T_{i} .
$$

In the formula, the superscript $p$ is state I and the superscript $l$ is state II.

Use each vector to redefine the energy input of the pillar before and after the excavation, and on this basis, derive the expression of the work done by the filling body and the top pillar to the pillar unit:

$$
d W_{\text {out }}=\left(\delta u_{i} T_{i}^{p}+\frac{1}{2} \delta u_{i} \delta T\right)_{i} d S .
$$

Integrate formula (2) to obtain

$$
W_{\text {out }}=\oiint_{S+S_{e}+S_{S}}\left(\delta u_{i} T_{i}^{p}+\frac{1}{2} \delta u_{i} \delta T_{i}\right) d S .
$$

Combined with the physical work done by the unit body in the pillar, the energy input is

$$
W=\oiiint_{V} X_{i} \delta u_{i} d V+\oiint_{S+S_{e}+S_{S}}\left(\delta u_{i} T_{i}^{p}+\frac{1}{2} \delta u_{i} \delta T_{i}\right) d S .
$$

On the basis of determining the expression of energy accumulation, the strain energy density of the pillar unit body at a certain time point in the interval between states I and II can be expressed as

$$
\phi=\frac{1}{2} \tau_{i j} e_{i j}
$$

After the excavation is completed, the strain energy density of state II can be expressed as

$$
\begin{aligned}
\phi_{\pi}= & \frac{1}{2}\left(\tau_{i j}^{p}+\delta \tau_{i j}\right)\left(e_{i j}^{p}+\delta e_{i j}\right)=\frac{1}{2}\left(\tau_{i j}^{p} e_{i j}^{p}+\delta \tau_{i j} e_{i j}^{p}+\tau_{i j}^{p} \delta e_{i j}\right. \\
& \left.+\delta \tau_{i j} \delta e_{i j}\right)=\frac{1}{2}\left(\phi^{p p}+\phi^{e p}+\phi^{p e}+\phi^{e e}\right) .
\end{aligned}
$$

In the process of ore deformation and destruction, energy transfer and release are key factors [19, 20]. From a mechanical point of view, the deformation and destruction process of rock is actually a process from local dissipation to local destruction and finally to the overall disaster. Therefore, combining the elastic release energy theory [21] (ERE) and the local energy release rate theory (LERR) to define energy accumulation, namely, 


$$
\begin{gathered}
U_{\pi}=\oiiint_{V} \phi_{\pi} d V U_{\pi}=\oiiint_{V} \phi^{p p} d V, \\
\mathrm{LERR}_{i}=U_{i \pi}-U_{i \pi}=\oiiint_{V}\left(\phi^{e p}+\phi^{p e}+\phi^{e e}\right) d V, \\
\mathrm{ERE}=\sum_{i=1}^{n}\left(\mathrm{LERR}_{i} \cdot V_{i}\right) .
\end{gathered}
$$

According to the principle of virtual work and the Gaussian divergence theorem [22], $\Phi_{p e}, \Phi_{e p}$, and $\Phi_{e e}$ are integrated in the pillar $V$ :

$$
\begin{aligned}
\oiiint_{V} \phi^{e p} d V & =\frac{1}{2} \oiiint_{V} \delta \tau_{i j} e_{i j}^{p} d V \\
& =\frac{1}{2}\left[\oiiint_{V} X_{i} u_{i}^{p} d V+\oiiint_{s+s_{e}+s_{s}}\left(\delta T_{i} u_{i}^{p}+\delta R_{i} u_{i}^{p}\right) d S\right] \\
\oiiint_{V} \phi^{p e} d V & =\frac{1}{2} \oiiint_{V} \tau_{i j}^{p} \delta e_{i j} d V \\
& =\frac{1}{2}\left[\oiiint_{V} X_{i} \delta u_{i} d V+\oiiint_{s+s_{e}+s_{s}}\left(T_{i}^{p} \delta u_{i}+R_{i}^{p} \delta u_{i}\right) d S\right] \\
\oiiint_{V} \phi^{e e} d V & =\frac{1}{2} \oiiint_{V} \delta \tau_{i j} \delta e_{i j}^{p} d V \\
& =\frac{1}{2}\left[\oiiint_{V} X_{i} \delta u_{i} d V+\oiint_{s+s_{e}+s_{s}}\left(\delta T_{i} \delta u_{i}+\delta R_{i} \delta u_{i}\right) d S\right] .
\end{aligned}
$$

Substituting equation (10) into equation (9) to simplify the strain energy accumulation expression based on the local energy release rate,

$$
\begin{aligned}
\operatorname{LERR}_{i}= & \frac{1}{2}\left[\oiiint_{V} X_{i}\left(u_{i}^{l}+\delta u_{i}\right) d V+\oiint_{s+s_{e}+s_{s}}\left(T_{i}^{p}+R_{i}^{p}\right) \delta u_{i}\right. \\
& \left.+\left(\delta T_{i}+\delta R_{i}\right) u_{i}^{l} d S\right] .
\end{aligned}
$$

In the process of ore body excavation, the transfer of energy between ore bodies is a dynamic fluctuating process. There will be errors in the calculation of the strain energy density difference before and after the failure of a single use unit. Therefore, the local energy release index is calculated on this basis. Amend and define the energy release coefficient $\left(\mathrm{LERC}_{i}\right)$ :

$$
\begin{aligned}
& \operatorname{LERR}_{i}=U_{i \pi}-U_{i \pi}, \\
& \operatorname{LERC}_{i}=\frac{U_{i \pi}-U_{i \pi}}{U_{i \pi}} .
\end{aligned}
$$

2.2. Judgment of Instability and Destruction of Pillar. According to the study of Yang et al. [23] corresponding to the mutation energy catastrophe criterion, when using the finite element program to analyze the strain energy of the rock mass, suppose the strain energy energy of the $m$ th unit body Gauss point after loading $k-1$ times is

$$
E_{m}(k)=\int_{V_{m}} \delta_{i j} \varepsilon_{i j} d V_{\mathrm{m}},
$$

where $\delta_{i j}$ and $\varepsilon_{i j}$ is the element stress and $V_{m}$ is the unit volume.

On this basis, it is assumed that the strain energy of $n$ units is

$$
\sum_{i=1}^{n} E_{m}(k)=\int_{V_{m}} \delta_{i j} \varepsilon_{i j} d V_{m}
$$

After the excavation is completed, the strain energy density of state II is represented by equation (6) for polynomial fitting analysis, and the result is

$$
\mathrm{ERE}=a_{0}+a_{1} n+a_{2} n^{2}+a_{3} n^{3}+a_{4} n^{4} .
$$

That is, the local energy release of the ore body increases by a polynomial of the fourth degree. The critical value of the instability and failure of the pillar adopts the cusp bifurcation theory as its criterion. Since the energy stored in the pillar is controlled by the horizontal and vertical variables, the following is

$$
n=x-\frac{a_{3}}{4 a_{4}} .
$$

Substituting formula (16) into formula (15), we obtain

$$
\begin{aligned}
\mathrm{ERE}^{\prime}= & x^{4}+\left(\frac{a_{2}}{a_{4}}-\frac{3 a_{3}^{2}}{8 a_{4}^{2}}\right) x^{2}+\left(\frac{a_{1}}{a_{4}}-\frac{a_{2} a_{3}}{2 a_{4}^{2}}+\frac{a_{3}^{3}}{8 a_{4}^{3}}\right) x=x^{4} \\
& +p x^{2}+q x,
\end{aligned}
$$

where $p$ is the control variable in the vertical direction and $q$ is the control variable in the horizontal direction.

According to the cusp catastrophe theory, the failure criterion of local energy catastrophe instability is

$$
\Delta=8 p^{3}+27 q^{2}=8\left(\frac{a_{2}}{a_{4}}-\frac{3 a_{3}^{2}}{8 a_{4}^{2}}\right)^{3}+27\left(\frac{a_{1}}{a_{4}}-\frac{a_{2} a_{3}}{2 a_{4}{ }^{2}}+\frac{a_{3}^{3}}{8 a_{4}^{3}}\right)^{2} .
$$

When $\triangle=0$, the energy mutation model is destroying the critical value of instability; when $\triangle>0$, the energy mutation model is stable; when $\Delta<0$, the energy mutation model is destabilizing and destroying.

\section{Numerical Test Plan for Subsequent Filling Energy Release in Phases}

3.1. Engineering Background. This section may be divided by subheadings. It should provide a concise and precise description of the experimental results and their interpretation, as well as the experimental conclusions that can be drawn. 
When an iron mine in East-Hebei area returned to the mining pillar by the method of subsequent filling in the empty field, after pulling the cutting groove, a "click, click" sound similar to the crack of the ice surface was heard on the spot, and the pillar suffered a large-scale integral collapse and instability. Although no casualties were caused, the equipment was buried, causing certain losses.

The mine adopts the staged empty field subsequent filling method for mining, and the ore rock has good stability. The ore body is a steeply inclined multilayer ore body, which has the characteristics of large changes in the thickness of the ore body and interlayer. The height of the stage is $60 \mathrm{~m}$, and the width of the pillar and the ore house are both $20 \mathrm{~m}$, the height of the bottom pillar is $5 \mathrm{~m}$, and the height of the top pillar is $10 \mathrm{~m}$. The mining method is adopted, that is, the mining room is firstly mined; then, the mining pillar is filled, and then, the empty area after the mining pillar is filled. The filling method adopts full tailings cementation filling, and the mechanical parameters of the filling body and the ore body are shown in Table 1 .

3.2. Establishment of the Numerical Model. In order to complete the full recovery stage of the empty field subsequent filling method, the mining room and pillar mining model are established, as shown in Figure 1. The boundary condition is to fix the displacement on both sides of the model and give the corresponding ground stress to the top column (Figure 1(a)). The single excavation time step is $20 \mathrm{~m}$, and the mining is carried out according to the backward mining sequence from both ends to the middle, that is, the mining room is first, the mining room is recovered, and the subsequent filling is carried out, and then, the pillar mining and subsequent filling operations are carried out, that is, the mining room is opened first. Then, it will be filled, followed by mining pillars 1 and 3 and, finally, mining pillar 2 .

When the stoping proceeds to the last section of the pillar, the schematic diagram of the model is shown in Figure 1(b). Due to the bleeding and sedimentation characteristics of the filler slurry, there is an unconnected headspace between the filler and the top pillar, and the height of the void is $\triangle h=4 \mathrm{~m}$.
3.3. Unloading Mechanical Model and Numerical Solution of Stress Components. As shown in Figure 1(a), after the cutting groove is excavated, the unloading effect causes the stress to redistribute in the pillars and the filling body. The stress reduction zone, the stress rise zone, and the original are formed in the headspace area where the filling body is not connected from the outside to the inside. The rock stress zone, and the top of the ore pillar forms a fracture zone, a plastic zone, and an elastic zone from shallow to deep $[24,25]$. According to the superposition principle, the stress increment at any point of the pillar can be decomposed into the sum of the additional stress and the original rock stress. The additional stress calculation model of the pillar is shown in Figure 2. In Figure 2, $k$ is the stress concentration factor, $H$ is the buried depth of the pillar, $L_{1}$ is the width of the limit equilibrium zone, $L_{2}$ is the distance from the cutting groove to the boundary of the elastic zone, and $\gamma$ is the bulk density of the overlying pillar.

Then, the pillar load expression is

$$
q_{i}(x)=k_{i} x+b_{i},
$$

where $\quad k_{1}=\left(K \gamma H-q_{1}\right) / L_{1}, b_{1}=q_{1}-\gamma H, k_{2}=-(k-1)$ $\gamma H /\left(L_{2}-L_{1}\right)$, and $b_{2}=(k-1) \gamma H L_{2} /\left(L_{2}-L_{1}\right)$.

Regarding the pillar as a homogeneous and isotropic body, the elastic-plastic finite element method is used in the numerical calculation, and the stress component at any point $Q(x, z)$ in the pillar under linear load is obtained through the principle of elasticity superposition [26]. As shown in Figure 2, taking the differential $\mathrm{d} \xi$ at $x=\xi$, the stress component caused by the small concentrated force $\mathrm{d} F$ at point $Q$ is as follows:

$$
\begin{aligned}
& d \sigma_{z}=-\frac{2 q_{i}(x) d \xi}{\pi} \frac{z^{3}}{\left(x^{2}+z^{2}\right)^{2}} \\
& d \sigma_{X}=-\frac{2 q_{i}(x) d \xi}{\pi} \frac{x^{2} z}{\left(x^{2}+z^{2}\right)^{2}} \\
& d \tau_{x z}=-\frac{2 q_{i}(x) d \xi}{\pi} \frac{x z^{2}}{\left(x^{2}+z^{2}\right)^{2}}
\end{aligned}
$$

Integrate formula (12) on the interval $\left(0, L_{1}\right)$ to obtain the additional stress caused by point $Q$ :

$$
\begin{aligned}
\Delta \sigma_{z 1}= & \int_{0}^{L_{1}}-\frac{2\left(k_{1} \xi+b_{1}\right)}{\pi} \frac{z^{3} d \xi}{\left[(x-\xi)^{2}+z^{2}\right]^{2}}=-\frac{\left(k_{1} x+b_{1}\right)}{\pi}\left[\arctan \frac{x}{z}-\arctan \frac{x-L_{1}}{z}+\frac{z x}{x^{2}+z^{2}}-\frac{z\left(x-L_{1}\right)}{\left(x-L_{1}\right)^{2}+z^{2}}\right] \\
& -\frac{k_{1} z^{3}}{\pi}\left[\frac{1}{x^{2}+z^{2}}-\frac{1}{\left(\left(x-L_{1}\right)^{2}+z^{2}\right.}\right], \\
\Delta \sigma_{x 1}= & \int_{0}^{L_{1}}-\frac{2\left(k_{1} \xi+b_{1}\right)}{\pi} \frac{z(x-\xi)^{2} d \xi}{\left[(x-\xi)^{2}+z^{2}\right]^{2}}=-\frac{\left(k_{1} x+b_{1}\right)}{\pi}\left[3 \arctan \frac{x}{z}-3 \arctan \frac{x-L_{1}}{z}+\frac{z x}{x^{2}+z^{2}}-\frac{z\left(x-L_{1}\right)}{\left(x-L_{1}\right)^{2}+z^{2}}\right]
\end{aligned}
$$


TABLE 1: Mechanical parameters of backfill and ore in a certain ore in Eastern Hebei province.

\begin{tabular}{lccccc}
\hline Name of ore rock & Shear modulus $(\mathrm{MPa})$ & Bulk modulus $(\mathrm{MPa})$ & Cohesion $(\mathrm{MPa})$ & Elastic modulus $(\mathrm{MPa})$ & Poisson's ratio \\
\hline Ore body & $3.32 \times 10^{3}$ & $4.62 \times 10^{3}$ & 1.72 & $8.03 \times 10^{3}$ & 0.21 \\
Surrounding rock & $4.39 \times 10^{3}$ & $1.57 \times 10^{3}$ & 2.38 & $6.98 \times 10^{3}$ & 0.26 \\
Filling body & $1.18 \times 10^{2}$ & $1.51 \times 10^{2}$ & 1.05 & $2.8 \times 102$ & 0.19 \\
\hline
\end{tabular}

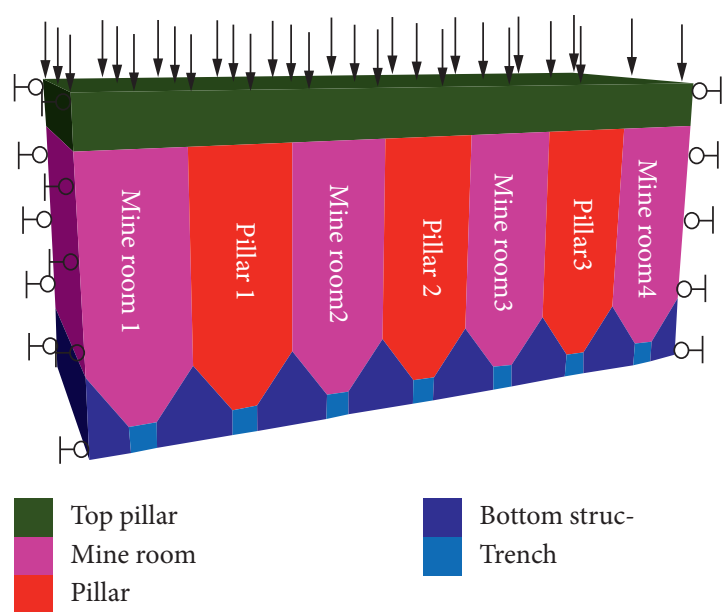

(a)

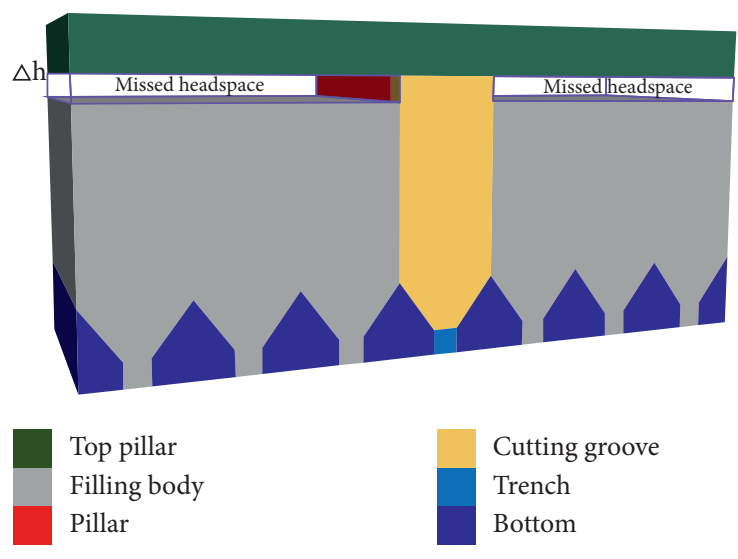

(b)

FIGURE 1: Numerical simulation model diagram. (a) Schematic diagram of boundary conditions. (b) Schematic diagram of stope model before cutting groove excavation

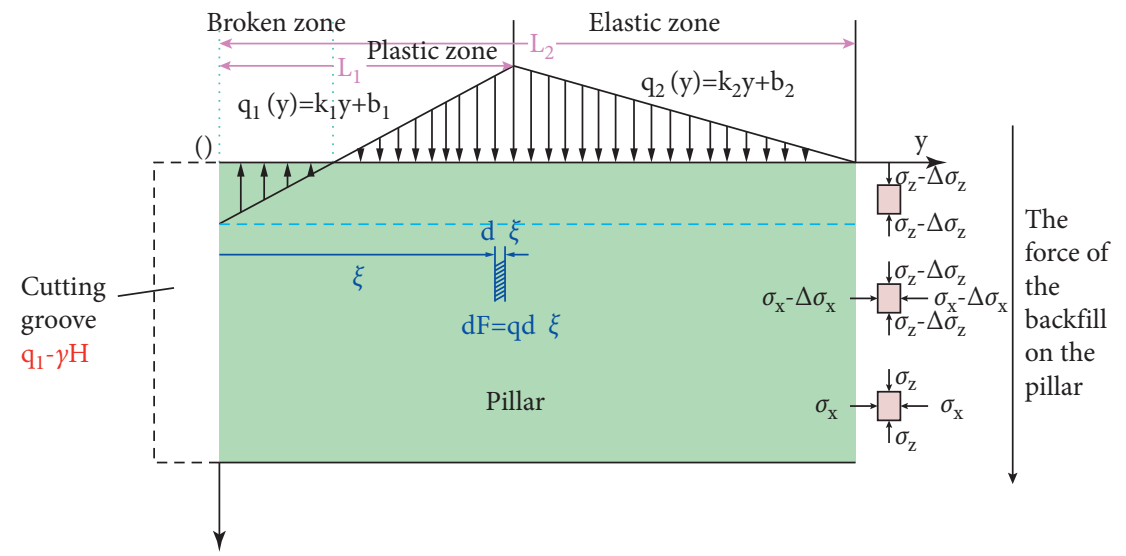

FIgURE 2: Mechanical model of cutting groove excavation unloading under filling condition.

$$
\begin{aligned}
& -\frac{k_{1} z^{3}}{\pi}\left[\frac{1}{x^{2}+z^{2}}-\frac{1}{\left(\left(x-L_{1}\right)^{2}+z^{2}\right.}\right]+\frac{k_{1} z}{\pi}\left\{\ln \left(x^{2}+z^{2}\right)-\ln \left[\left(x-L_{1}\right)^{2}+z^{2}\right]\right\}, \\
\Delta \tau_{x z 1}= & \int_{0}^{L_{1}}-\frac{2\left(\left(k_{1} \xi+b_{1}\right)\right)}{\pi} \frac{z^{2}(x-\xi) d \xi}{\left[(x-\xi)^{2}+z^{2}\right]^{2}}= \\
& -\frac{k_{1} z}{\pi}\left[\frac{z x}{x^{2}+z^{2}}-\frac{z\left((x-L)_{1}\right)}{\left(x-L_{1}\right)^{2}+z^{2}}-\left(\arctan \frac{x}{z}-\arctan \frac{x-L_{1}}{z}\right)\right]+\frac{\left(k_{1} x+b_{1}\right) z^{2}}{\pi}\left[\frac{1}{x^{2}+z^{2}}-\frac{1}{\left(\left(x-L_{1}\right)^{2}+z^{2}\right.}\right] .
\end{aligned}
$$


In the same way, the additional stress caused by the $Q$ point on the interval $\left(L_{1}, L_{2}\right)$ can be obtained.

The stress state of the pillar after the excavation of the cutting slot can be characterized by the sum of the additional stress and the original rock stress, namely,

$$
\begin{aligned}
\sigma_{z} & =\Delta \sigma_{z 1}+\Delta \sigma_{z 2}+\gamma H, \\
\sigma_{x} & =\Delta \sigma_{x 1}+\Delta \sigma_{x 2}+\gamma H, \\
\tau_{x z} & =\Delta \tau_{x z 1}+\Delta \tau_{x z 2}+\gamma H .
\end{aligned}
$$

\section{Analysis of Energy Release Mechanism of Excavation Unloading}

4.1. The Law of Energy Change during Excavation and Unloading. The law of energy release during the two-step process of returning to the mining pillar by the subsequent filling method of the staged mine room is explored. Assign the model to an ideal elasto-plastic constitutive model to calculate the initial ground stress. First, carry out the excavation simulation test of the mining roadway. After the calculation has gone through $1.8 \times 10^{3}$ time steps, the initial energy distribution of the model is obtained as shown in Figure 3.

It can be seen from Figure 3(a) that when the mining roadway is formed, strain energy accumulates in a large amount around the mining roadway and the trench, and the peak density reaches $1.12 \times 10^{4} \mathrm{~J} / \mathrm{m}^{3}$; as shown in Figure 3(b), after the excavation is completed, the top pillar pressure is borne by the pillar, and the peak strain energy density in the pillar reaches $4.69 \times 10^{4} \mathrm{~J} / \mathrm{m}^{3}$; as shown in Figure 3(c), when the middle pillar is mined, both sides of the pillar have been filled. At this time, pillar 2 supports the roof under the condition of filling on both sides, and its internal strain energy density is as high as $2.36 \times 10^{5} \mathrm{~J} / \mathrm{m}^{3}$, and the strain energy accumulates at the top of the pillar.

Schemes follow another format. If there are multiple panels, they should be listed as (a) description of what is contained in the first panel and (b) description of what is contained in the second panel. Figures should be placed in the main text near to the first time they are cited. A caption on a single line should be centered.

Take a small unit body in pillar 2, and its force in the twostep stoping process is shown in Figure 4. It can be seen that the mechanical environment of the ore pillar has undergone complex changes during this process, and the analysis of the strain energy release in Figure 3 shows that the ability of the ore pillar to absorb energy is significantly improved under the action of the filling body, which changes with the force environment of the ore pillar. There is a close relationship.

After the excavation of the cutting groove, it is not yet clear whether the pillar under high-stress load causes the overall instability due to the sudden change in the energy release rate of the end face. Therefore, it is necessary to determine the mechanical action mechanism and the law of energy accumulation and release before and after transient unloading of the excavation face. We conduct detailed investigations.
4.2. Research on Transient Unloading Energy Release of Pillar under the Action of Backfill. The supporting effect of the backfill on the pillar is mainly lateral restraint. Due to the bleeding and settlement characteristics of the backfill, there is an unconnected headspace area, and the concentration of each part of the backfill varies greatly. Pillar 2 is divided into 0 from top to bottom: $0-1 / 4,1 / 4-2 / 4,2 / 4-3 / 4$, and $3 / 4-1$, four partitions, as shown in Figure 5 . The stress components of each subarea are calculated, and the effect mechanism of the filling body on the pillar during the excavation and cutting groove is analyzed according to the deviation of the peak point of each stress component.

Combine formula (6) to calculate the energy density of the pillar after excavation. As shown in Figure 5, the energy accumulation area is mainly located at $1 / 4$. Because the filling body is not connected to the top, it is cut at 2/4 and 3/ 4. The peak stress component is the highest.

According to formula (20), the distribution curve of each stress component of the pillar at different heights from the top pillar is calculated. The peaks of the horizontal and vertical stress components have similar distribution rules, and the peak points are shifted to different degrees, but the vertical stress component varies with the height. The peak intensity rises as the descending height, and the horizontal stress component decreases as the height drops, as shown in Figure 6. The stress has a single peak distribution. Due to the transient excavation unloading effect of the cutting groove, the pillar (3/4 position) is greatly affected by the lateral restraint of the filling body, and the degree of plasticity is low. As the distance to the top pillar gets closer ( $1 / 4$ point), due to the characteristics of bleeding settlement where the filling body is not completely connected to the top, the lateral restraint on the pillar is significantly reduced, the peak point appears to move outward, and the stress in the crushing zone is lower than the original rock stress, and plastic failure is relatively large, as shown in Figure 6(a).

The shear stress presents a double-peak distribution, peak point one moves from $x=1.9 \times 10^{3}$ time step to $x=0.8 \times 10^{3}$ time step, peak point two moves from $x=5.0 \times 10^{3}$ time step to $x=6.2 \times 10^{3}$ time step, and the peak value gradually decreases with the depth. Comparing the various stress components in the crushing zone, the peak shear stress in the crushing zone is larger, and the closer it is to the top pillar, the more obvious, indicating that the top of the pillar is more likely to produce a shear failure zone than other stress components.

Through the above analysis of the various stress components, it is found that the vertical stress and the tangential stress have a greater impact on the stress state of the pillar, and the distribution of the tangential stress is more consistent with the accumulation of strain energy in the pillar. Because the accumulation and release of energy have obvious time effects, the effect of the time of stress component action must be considered to correspond to the local release rate of variable energy.

Based on the time series of the energy accumulation and release of the pillar, the axial stress on the pillar is used as the basis for the calibration time, and the time effect of the sudden change of energy release is analyzed in combination with the 


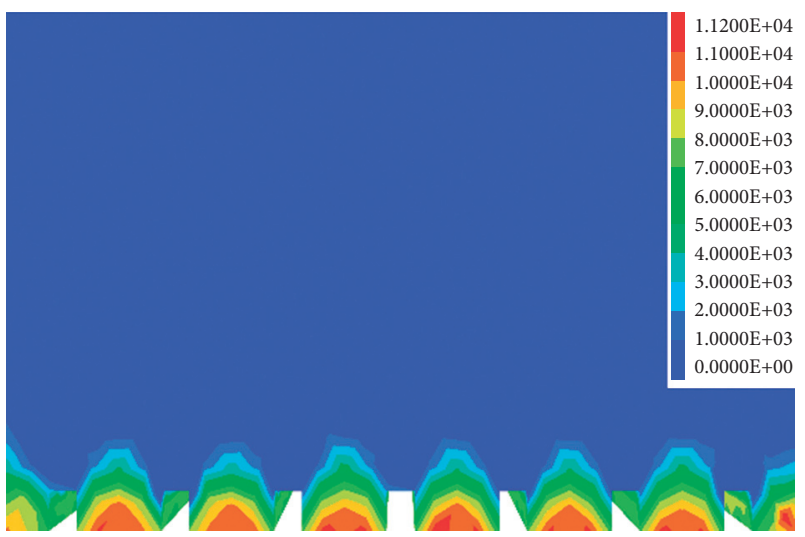

(a)

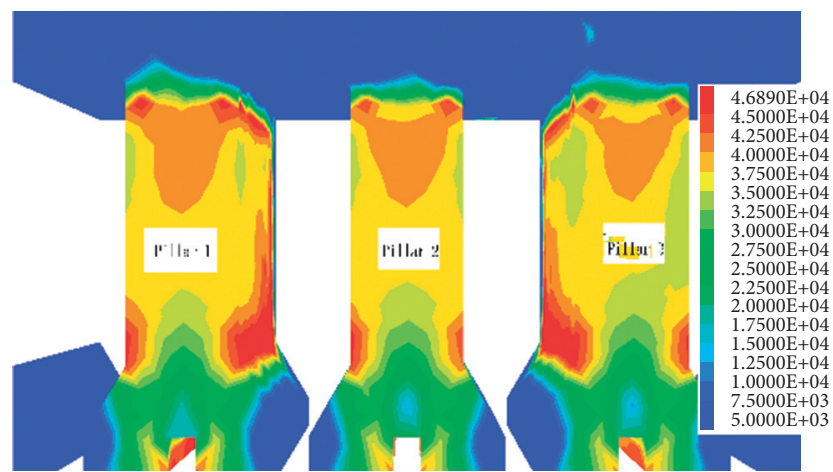

(b)

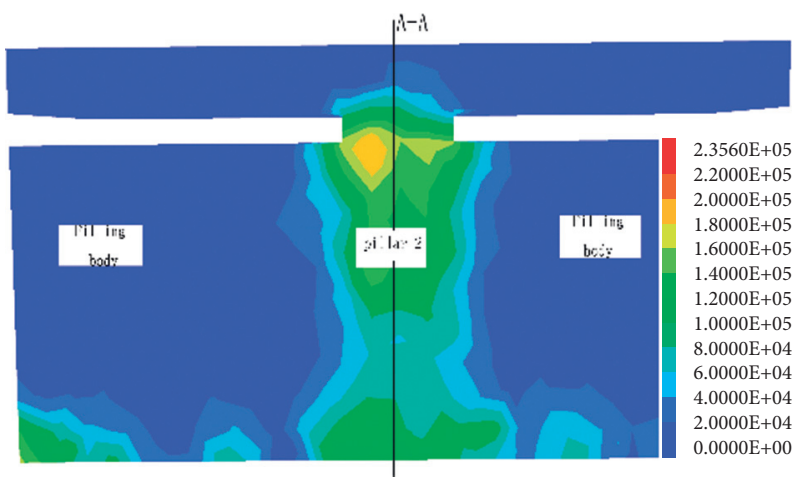

(c)

Figure 3: Energy density distribution in each stage of stoping. (a) Energy distribution after the formation of the exit roadway. (b) Energy distribution after mining. (c) Energy distribution before excavation of cutting groove.

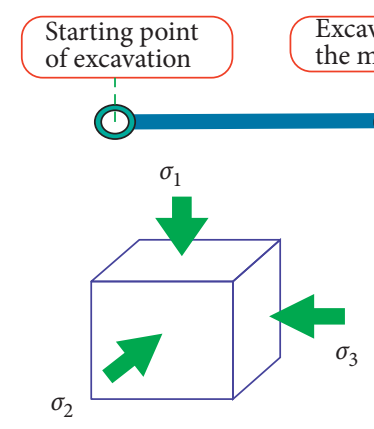

(a)

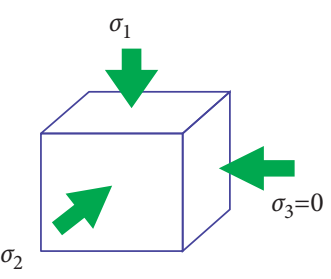

(b)

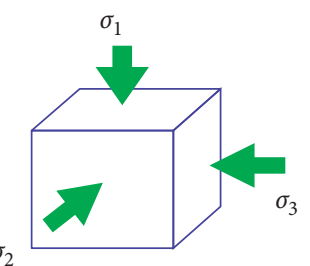

(c)
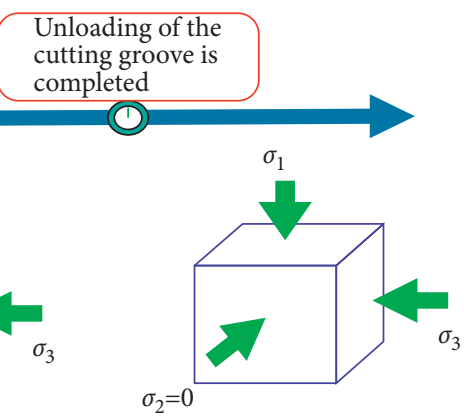

(d)

FIGURE 4: Stress variation of pillar at each stage of stoping.

stress state. Set up three excavation points, as shown in Figure 7, namely: $1.0 \times 10^{3}$ time steps before the peak axial stress; excavation at the peak; and $1.0 \times 10^{3}$ time steps after the peak.

It can be seen from Figure 7(a) that the strain energy density is always at a relatively low level during pre-peak excavation. At this time, the pillar waiting time is short, the tangential stress acts on the pillar within a short time, the energy accumulation in the shear failure zone is not significant, the final energy release rate reaches $9.3 \mathrm{~kJ} / \mathrm{m}^{3}$, and a small amount of plastic zone appears at $1 / 4$ of the pillar. Figure 7 (b) shows that the energy release rate during peak excavation rises to $16.9 \mathrm{~kJ} / \mathrm{m}^{3}$, and the strain energy release time is significantly shortened. At this time, a large number of plastic zones have appeared at $1 / 4$ of the pillar. In Figure $7(\mathrm{c})$, it can be seen that, with the increase of the waiting time of the mine pillar, the accumulation of strain energy is greatly increased, the energy release time is shortened, and the local energy release rate reaches $25.9 \mathrm{~kJ} /$ $\mathrm{m}^{3}$, which has formed a "catastrophic" release, and the entire pillar has plastic failure.

Comparing (a), (b), and (c), it can be seen that the time effect of energy accumulation is more significant, which is manifested as the more energy accumulated in the shear failure zone with time, the more energy is released after 


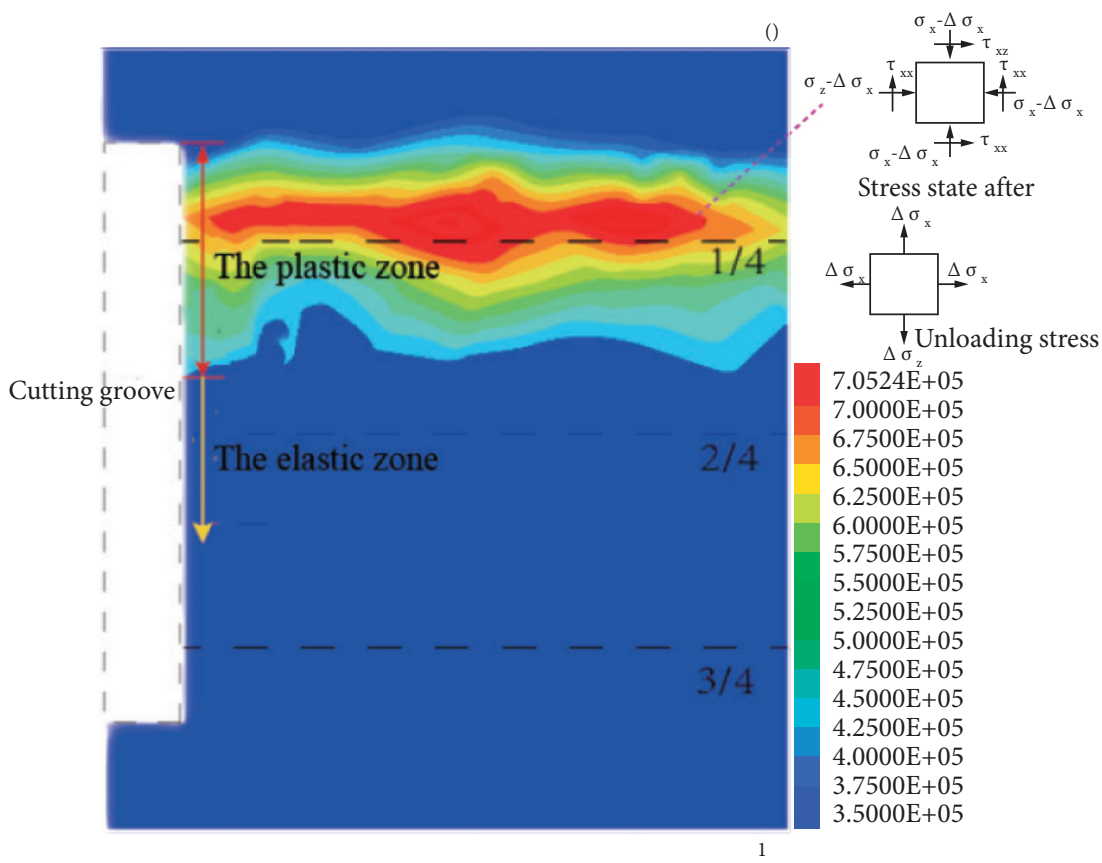

FIGURE 5: Energy distribution nephogram of the unloading profile of pillar excavation face.

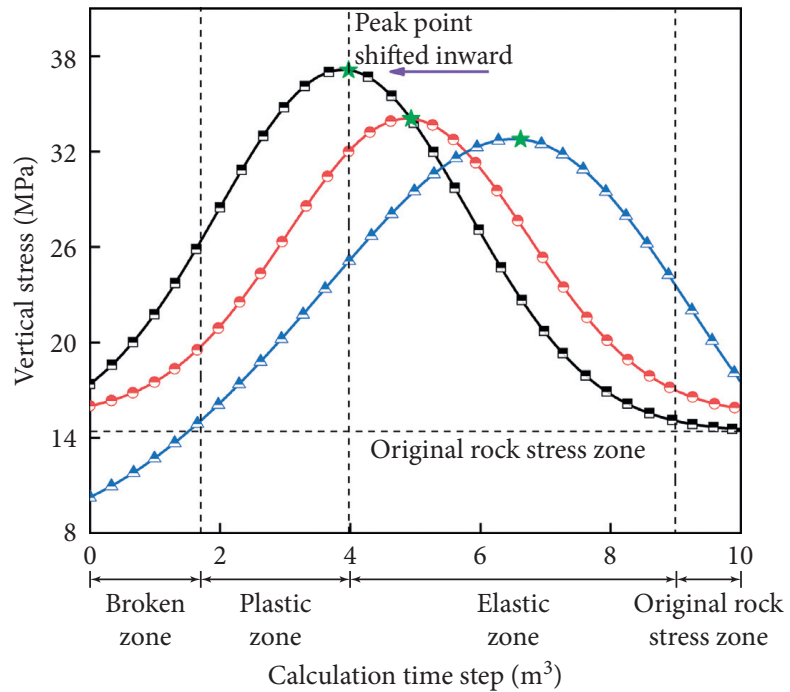

$\star \quad$ Peak point

- $-3 / 4$

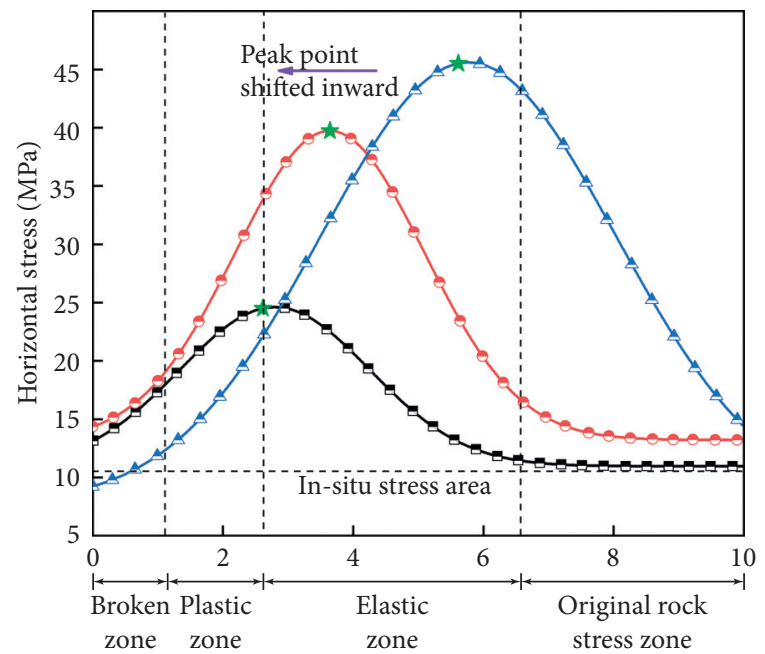

Calculation time step $\left(\mathrm{m}^{3}\right)$ $\begin{array}{ll}\star \quad \text { Peak point } & -\bullet-2 / 4 \\ - & -A / 4\end{array}$

(b)

Figure 6: Continued. 


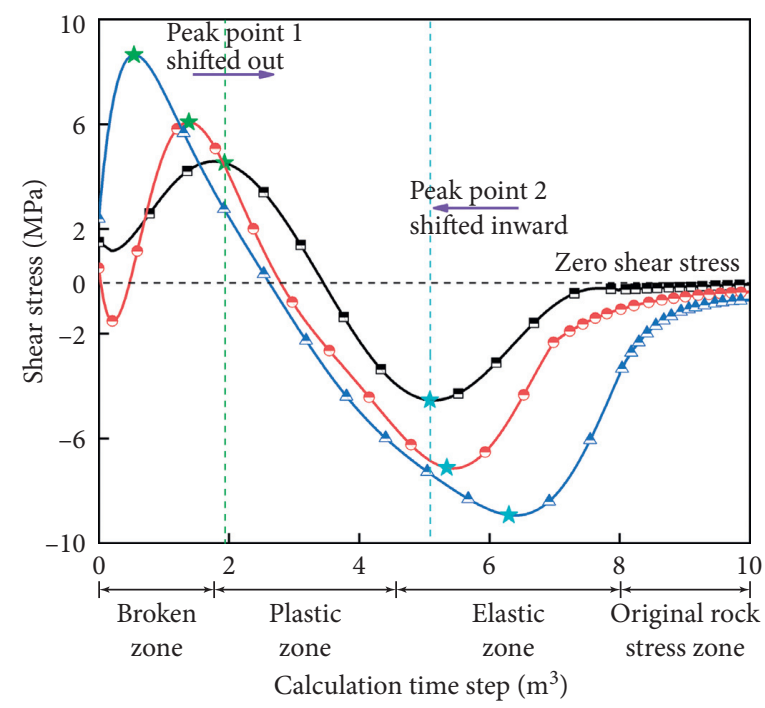

$\begin{array}{ll}\star \quad \text { Peak point } 1 & -\bullet-2 / 4 \\ \star \quad \text { Peak point } 2 & -\Delta-1 / 4\end{array}$

-e- $3 / 4$

(c)

FIGURE 6: Distribution curve of stress component in different parts of pillar. (a) Vertical stress. (b) Horizontal stress. (c) Shear stress.

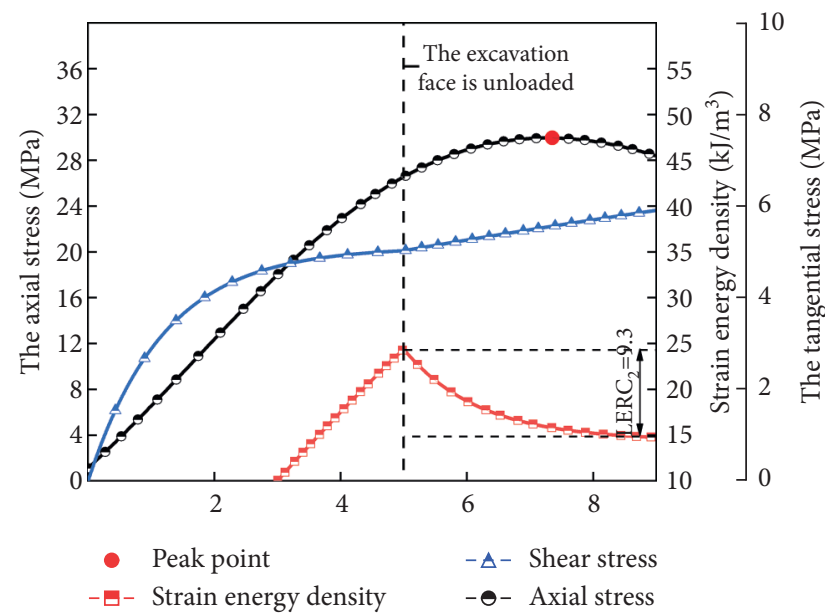

(a)

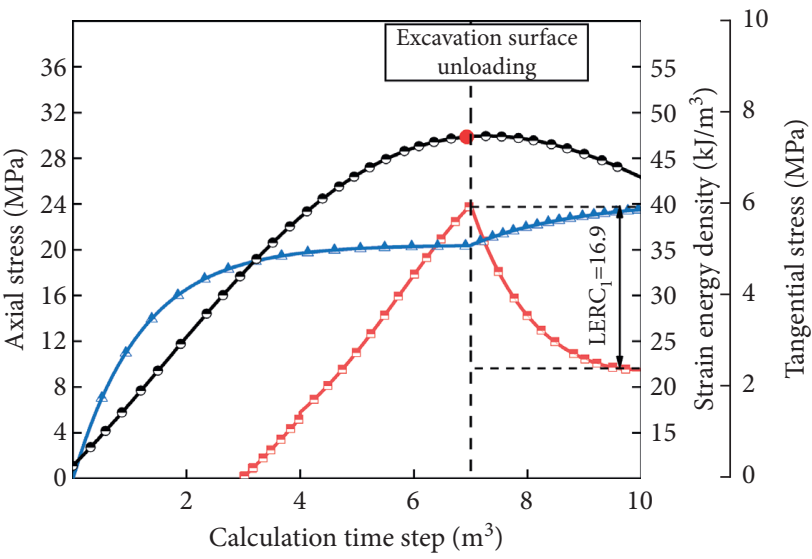

- Peak axial stress $\quad-\Delta-$ Shear stress

- - - Strain energy density $\quad$ - $\bullet-$ Axial stress

Figure 7: Continued. 


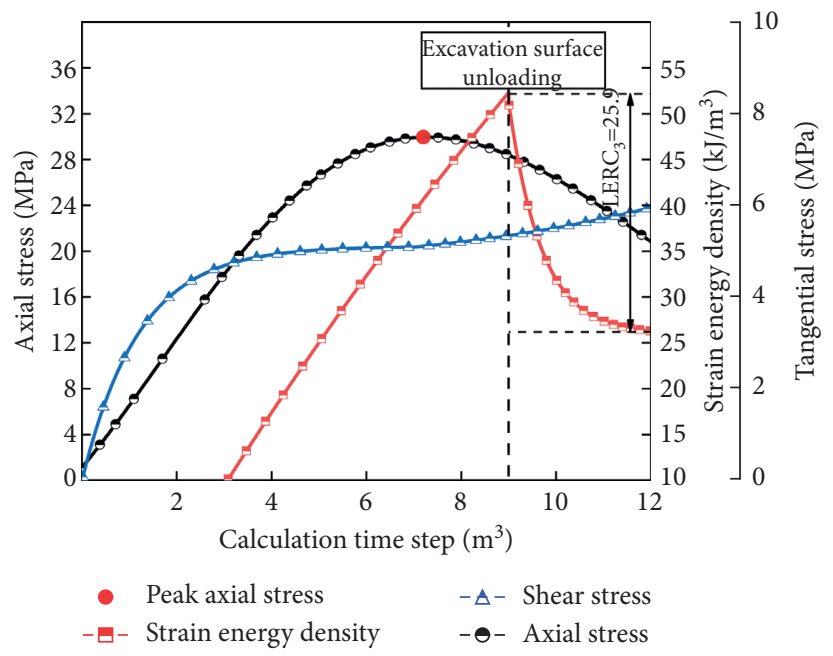

(c)

Figure 7: Local energy release rate curve of the pillar. (a) Excavation in front of the peak. (b) Peak excavation. (c) Excavation after the peak.

TABLE 2: determination value of local energy mutation of pillar.

\begin{tabular}{lccccc}
\hline Excavation point & $a_{1}$ & $a_{2}$ & $a_{3}$ & $a_{4}$ & \multicolumn{1}{c}{} \\
\hline Before the peak & 237.74 & 260.47 & -51.19 & 3.54 & $2.03 \times 10^{5}$ \\
Peak & -316.73 & 382.17 & -84.21 & 5.94 & $-2.83 \times 10^{6}$ \\
Post-peak & 1250.1 & 242.59 & 19.92 & -0.44 & $-2.13 \times 10^{9}$ \\
\hline
\end{tabular}

excavation; the greater the tangential stress, the shorter the local energy release time; the large amount of accumulated energy released in a short time will cause mutations, which will lead to the instability of the pillar.

4.3. Criterion of Instability and Failure of Pillar Based on Local Release Energy. The cusp catastrophe model analysis of the local energy release rate can determine the degree of instability and damage of the pillar. According to formula (15) in Section 2.2, the 4th order polynomial fitting of the local energy release rate before the peak, at the peak, and postpeak excavation is performed. We get the following 4th degree polynomial:

$$
\begin{array}{r}
\text { before the peak : } \text { LERC }_{2}=3.54 x^{4}-51.19 x^{3}+260.47 x^{2}+237.74 x+79.29, \\
\text { peak : } \text { LERC }_{1}=5.94 x^{4}-84.21 x^{3}+382.17 x^{2}-316.73 x+174.62, \\
\text { post }- \text { peak : } \text { LERC }_{3}=-0.44 x^{4}+19.92 x^{3}-242.59 x^{2}+1250.1 x+40.44 .
\end{array}
$$

In-depth analysis of the mutation mechanism of local energy release is carried out to verify the degree of influence of energy release on the instability of the pillar. According to the cusp mutation discriminant formula (18), the coefficients $a_{i}$ of the main parts and the control variables $p$ and $q$ are calculated, and the local energy release rate fitting formulas (23), (24), and (25) are obtained, and the polynomial coefficients calculated the discriminant value $\triangle$ (Table 2 ) which can effectively reflect the degree of local energy release.

It can be seen from the table that the pillars are relatively stable after excavation before the peak $(\triangle>0)$, and the pillars have been destabilized and damaged after excavation at the peak and after the peak $(\triangle<0)$, and the absolute value of the discrimination after the peak is obviously greater than that at the peak. Excavation means that the degree of damage to the pillars excavated after the peak is the most severe.

The cusp mutation discriminant value effectively verifies the time effect of energy accumulation and release. The longer the stress component is, the more energy is released when the excavation surface is unloaded and the more serious the damage is.

In summary, the underground space structure system of filling body-pillar-filling body is formed during the filling mining process of an iron mine in east East-Hebei. 
Because the filling body is not connected to the roof, the top exposed pillar is not covered by the filling body, and a good lateral direction is not formed. Constraints result in a sharp increase in the tangential stress component of this part, resulting in a large accumulation of strain energy, and the longer the ore pillar is to be mined, the longer it supports the stope and the more internal energy accumulates. At the moment of excavation of the cutting groove, the exposed area of the pillar suddenly increases, causing an "abrupt increase" in the energy release rate and causing damage to the strain energy accumulation place (1/4 of the pillar from the top to the bottom). The damage increases with the strain energy. The change of the release path is transferred to the empty surface of the cutting groove, which eventually leads to the overall collapse of the pillar.

\section{Conclusion}

(1) Using the theory of stress component to decompose the high stress on the pillar into horizontal stress, vertical stress, and tangential stress, we point out that the tangential stress component is the main reason for the accumulation of strain energy in the pillar, reasonably partitioning the pillar $(0,1 / 4,2 / 4,3 / 4,1)$. It is found that the highest tangential stress is $1 / 4$ zone, and the initial failure position of the pillar after transient unloading is determined.

(2) By adjusting the unloading point to change the time of high stress acting on the pillar, it is found that the duration of the tangential stress component directly affects the strain energy density, which is manifested as the longer the time, the higher the strain energy density; the cusp catastrophe model shows unloading. The higher the front strain energy density, the more serious the plastic failure after plastic unloading, indicating that the degree of failure is determined by the strain energy density.

(3) In the actual mining process of the two-step mining pillar, measures such as realizing filling and roofing were taken to effectively reduce the peak tangential stress component at the top of the pillar and to optimize the mining sequence of the pillar to reduce the duration of high stress acting on the pillar to reduce the strain energy density at the top of the pillar before excavation of the cutting groove, so as to avoid accidents after transient unloading of highstress pillars.

\section{Data Availability}

The data used to support the findings of this study are available from the corresponding author (Guanghua Sun) upon reasonable request.

\section{Conflicts of Interest}

The authors declare that there are no conflicts of interest.

\section{Authors' Contributions}

Chenyang Liu synthesized study data and wrote the article. Guanghua Sun formulated overarching research goals and had oversight and leadership responsibility. Yufan Feng designed and validated computer programs, Yue Wang drew figures. Peng Liang provided the funding and the methodology. Jinxia Zhang carried out literature search and data acquisition and collected important background information. All authors have read and approved the content of the manuscript.

\section{Acknowledgments}

This work was financially supported by the National Natural Science Foundation of China (51774138) and Natural Science Foundation of Hebei (E2020209166).

\section{References}

[1] B. Peter, F. Bernier, P. Lebon, and C. Derek Martin, "The excavation damaged zone in clay formations time-dependent behaviour and influence on performance assessment," Physics and Chemistry of the Earth, vol. 32, no. 8, 2006.

[2] I. Einav, G. T. Houlsby, and G. D. Nguyen, "Coupled damage and plasticity models derived from energy and dissipation potentials," International Journal of Solids and Structures, vol. 44, no. 7, 2006.

[3] J.-A. Wang and H. D. Park, "Comprehensive prediction of rockburst based on analysis of strain energy in rocks," Tunnelling and Underground Space Technology incorporating Trenchless Technology Research, vol. 16, no. 1, 2001.

[4] R. Mitri, H. S. Tang, and B. Simon, "FE modelling of mininginduced energy release and storage rates," Southern African Institute of Mining and Metallurgy, vol. 99, no. 2, 1999.

[5] N. G. Cook, E. Whoek and J. P. G. Pretorius, Rock mechanics applied to the study of rockbursts," Journal of the South African Institute of Mining and Metallurgy, vol. 66, no. 10, pp. 436-528, 1996.

[6] A. F. Revuzhenkor and S. V. Klishin, "Energy flux lines in a deformable rock mass with elliptical openings," SP MAIK Nauka/Interperiodica, vol. 45, no. 3, 2009.

[7] I. B. Tulu and K. A. Heasley, "Investigating the mechanics of pillar loading through the analysis of in-situ stress measurements," in Proceedings of the 45th US Rock Mechanics, pp. 20-25, [s.n., San Francisco, California, June 2011.

[8] N. P. Kripakov, M. C. Sun, and D. A. Douato, "ADNIA applied toward simulation of progressive failure in underground mine structure," Computers \& Structures, vol. 56, no. 2/3, pp. 329-344, 1995.

[9] M. N. Toksoz and H. H. Kehrer, "Tectonic strain release by underground nuclear explosions and its effect on seismic discrimination," Geophysical Journal International, vol. 31, no. 1/3, pp. 141-161, 1972.

[10] J. B. Walsh, "Energy changes due to mining," International Journal of Rock Mechanics and Mining Sciences \& Geomechanics Abstracts, vol. 14, no. 1, pp. 25-33, 1977.

[11] J. A. L. Napier, "Energy changes in a rockmass containing multiple discontinuities," Journal of the South African Institute of Mining and Metallurgy, vol. 91, no. 5, pp. 145-157, 1991.

[12] Y. Sun, Yu Yang, and P. Wang, "Energy and fatigue damage evolution of sandstone under different cyclic loading 
frequencies," Shock and Vibration, vol. 2021, Article ID 5585983, 2021.

[13] Y. Zhang, J. Li, G. Ma, S. Liu, and Y. Wang, "Unloading mechanics and energy characteristics of sandstone under different intermediate principal stress conditions," Advances in Civil Engineering, vol. 2021, Article ID 5577321, 2021.

[14] H. An-Zeng and M.-Q. You, "Rock failure due to energy release during unloading and application to underground rock burst control," Tunnelling and Underground Space Technology incorporating Trenchless Technology Research, vol. 16, no. 3, 2001.

[15] I. R. Kivi, M. Ameri, and H. Molladavoodi, "Shale brittleness evaluation based on energy balance analysis of stress-strain curves," Journal of Petroleum Science and Engineering, vol. 167, pp. 1-19, 2018.

[16] J. Fu, W. Song, and Y. Tan, "Discrimination criterion of local energy release for deep goaf instability considering unloading stress path," Chinese Journal of Rock Mechanics and Engineering, vol. 35, no. 02, pp. 217-224, 2016.

[17] B. Mahanta, A. Tripathy, V. Vishal, T. N. Singh, and P. G. Ranjith, "Effects of Strain Rate on Fracture Toughness and Energy Release Rate of Gas shales," Engineering Geology, vol. 218, pp. 39-49, 2017.

[18] K. Ali, P. Mehdi, and S. B. Anne, "Review of Design Parameters for Discontinuous Numerical Modelling of Excavations in the Hawkesbury Sandstone," Engineering Geology, vol. 288, Article ID 106158, 2021.

[19] Q. Li, B. Xiang, and N. Jiang, "Rockburst prediction on the superimposed effect of excavation accumulation energy and blasting vibration energy in deep roadway," Shock and Vibration, vol. 2021, Article ID 6644590, 2021.

[20] M. Soleiman Dehkordi, K. Shahriar, P. Moarefvand, and M. Gharouninik, "Application of the strain energy to estimate the rock load in squeezing ground condition of Eamzade Hashem tunnel in Iran," Arabian Journal of Geosciences, vol. 6, no. 4, 2013.

[21] S. Guo-shao, F. Xia-ting, Q. Jiang, and C. Guo-qing, "Study on a new index of local energy release rate for stability analysis and optimization of underground engineering under high insitu stress," Chinese Journal of Rock Mechanics and Engineering, vol. 25, no. 12, pp. 2453-2460, 2006.

[22] J. R. Barber, Elasticity, pp. 425-448, Springer, Berlin/Heidelberg, Germany, 1992.

[23] G. Yang, X. Li, Q. Wang, and S. Li, "Energy catastrophe criterion of underground stope instability and its application," Journal of Mining and Safety Engineering, vol. 25, no. 03, pp. 268-271+276, 2008.

[24] H. Xu, X.-T. Feng, C. Yang, X. Zhang, Y. Zhou, and Z. Wang, "Influence of initial stresses and unloading rates on the deformation and failure mechanism of Jinping marble under true triaxial compression," International Journal of Rock Mechanics and Mining Sciences, vol. 117, 2019.

[25] M. Diederichs, P. Kaiser, and E. Eberhardt, "Damage initiation and propagation in hard rock during tunnelling and the influence of near-face stress rotation," International Journal of Rock Mechanics and Mining Sciences, vol. 41, no. 5, 2004.

[26] A. I. Chanyshev and I. M. Abdulin, "STRESS-STRAIN behavior OF rocks from the measurements OF vectors OF the cauchy stresses and displacements at the boundary OF an underground excavation," Journal of Mining Science, vol. 57, no. 1, 2021. 